\title{
Phylogeny of the Hymenoptera (Insecta): The state of the art
}

\author{
FREDRIK RonQuist
}

\begin{abstract}
Ronquist, F. (1999). Phylogeny of the Hymenoptera (Insecta): The state of the art. Zoologica Scripta 28, 3-11.

The Hymenoptera form one of the major insect orders in terms of species diversity and they are also of great ecological and economic importance, notably as pollinators and natural enemies of pests. Phylogenies provide an essential framework for systematic, comparative and evolutionary research on hymenopterans. Here, I summarise what we know about the higher-level phylogeny of the Hymenoptera based on presentations given at a recent symposium on hymenopteran phylogenetics. I identify agreement and conflict among morphological and molecular analyses and suggest important priority areas for future research.

Fredrik Ronquist, Department of Systematic Zoology, Evolutionary Biology Centre, Uppsala University, Norbyvägen 18D, SE-75236 Uppsala, Sweden. fredrik.ronquist@zoologi.uu.se
\end{abstract}

\section{Introduction}

Phylogenetic research is often concentrated on small taxonomic groups, such as genera, but higher-level phylogenies are also important in many contexts. Higher phylogenies provide the basis for natural and stable higher classifications. They allow accurate circumscription of smaller monophyletic groups suitable for detailed taxonomic and revisionary work, and identify possible outgroups for character comparison. Higher phylogenies are also needed in reconstructing the evolution of important biological characters and are indispensable in the study of rare evolutionary events and major evolutionary trends.

The Hymenoptera are one of the most species-rich insect orders, boasting well above 100000 described species (Gaston 1991). Hymenopterans are found in most terrestrial environments and play key roles in many ecosystems, notably as pollinators of flowering plants and as parasitoids and predators of phytophagous insects. Some species cause significant damage to plants used in forestry and agriculture, while others are used as efficient biocontrol agents. Because of their importance, there has been a considerable amount of research on hymenopterans, covering almost all possible aspects. For a long time, however, the higher-level phylogeny of the group was poorly known. An important reason was the lack of rigorous methods of phylogenetic analysis, but there was also a lack of good comparative studies providing informative data. The two last decades have seen rapid progress in our understanding of higher hymenopteran phylogeny based primarily on detailed comparative morphological work on extant and extinct forms. Recently, molecular data have also contributed significantly. Yet, many aspects of the higher phylogeny of the Hymenoptera remain unclear.

With the intention to summarise our current understanding of hymenopteran phylogeny, I invited leading phylogeneticists from around the world to come to a symposium and workshop entitled 'Phylogeny of the Hymenoptera: The State of the Art' at the Department of Zoology in Uppsala during March 4-6, 1998 (Fig. 1). Many of the papers presented at the symposium are published in this issue of Zoologica Scripta. This introductory paper briefly summarises what we know about higherlevel hymenopteran phylogeny, largely based on the symposium papers, and attempts to point out important areas for future research.

\section{The state of the art}

For simplicity, the following summary is almost exclusively restricted to extant forms. See Rasnitsyn (1988) and Ronquist et al. (1999) for discussion of the position of higher taxa of fossil hymenopterans.

\section{Monophyly and phylogenetic position of the Hymenoptera}

The Hymenoptera form one of the most distinct and well defined insect orders and have long been perceived as a natural group. Sixteen morphological autapomorphies of hymenopterans are currently known (Vilhelmsen 1997) and hymenopteran monophyly is also well supported by comprehensive molecular analyses (Whiting et al. 1997). 


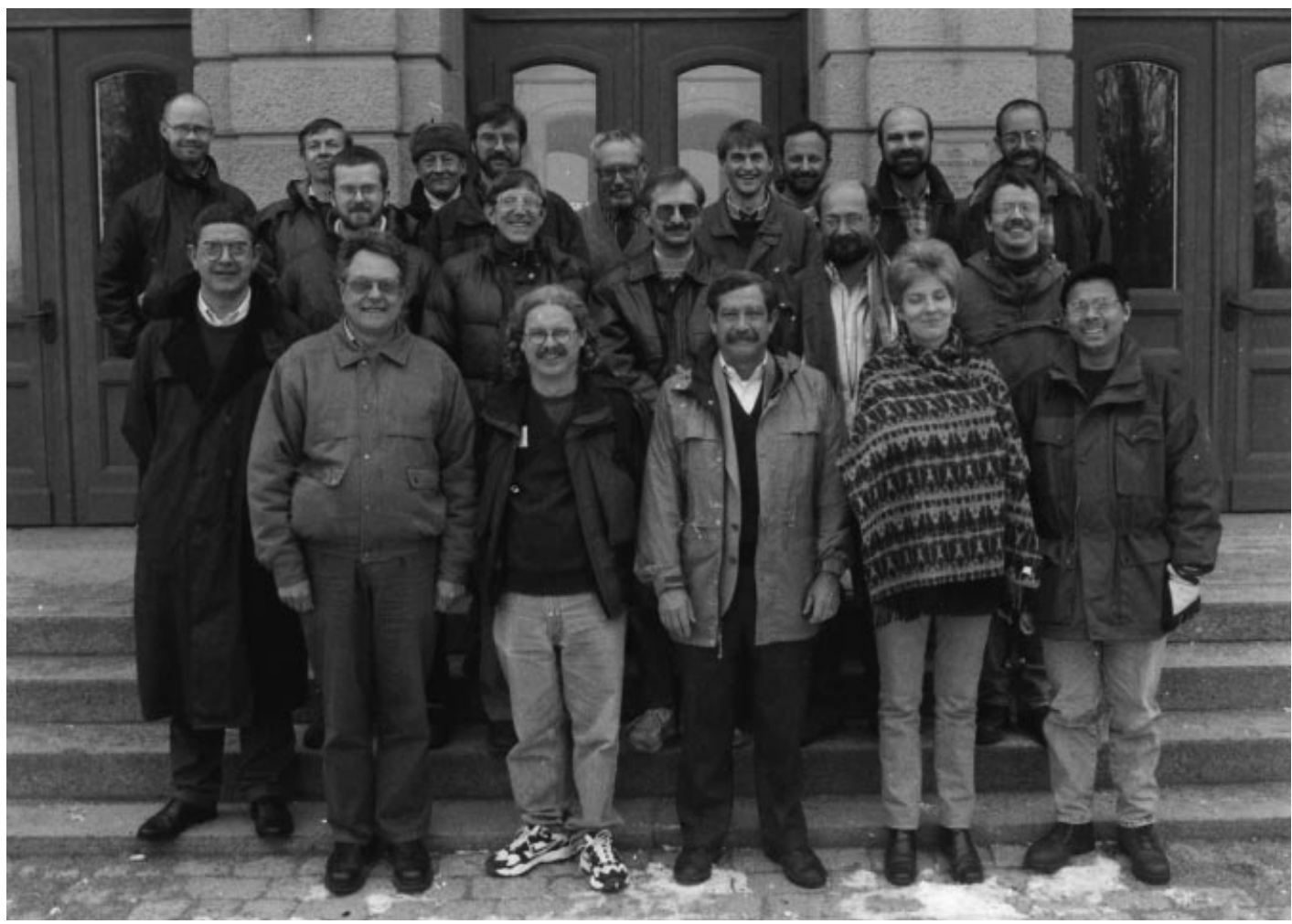

Fig. 1 Participants in the symposium and workshop 'Phylogeny of the Hymenoptera: The state of the art' in Uppsala, March 4-61998. Upper row (from left): Johan Liljeblad, Donald Quicke, Ferdinando Bin, Göran Nordlander, Alexandr Rasnitsyn, Fredrik Ronquist, Nunzio Isidoro, Hasan Basibuyuk, Mark Dowton. Mid row: Mike Fitton, Johan Liljeblad, Robert Wharton, Gary Gibson, John Heraty, Lars Vilhelmsen. Bottom row: Denis Brothers, James Carpenter, James Woolley, Nina Laurenne, Zhiwei Liu.

It has been clear for some time that the Hymenoptera constitute a basal lineage among the holometabolous (endopterygote) insect orders. Recent morphological and molecular analyses indicate that the Hymenoptera are the sister group of the Mecopterida, an enormously diverse lineage consisting of the orders Trichoptera, Lepidoptera, Diptera, Siphonaptera, Mecoptera and, possibly, the Strepsiptera (Kristensen 1991; Whiting et al. 1997). The only holometabolous insects that fall outside of the Mecopterida + Hymenoptera are the Coleoptera and the Neuropterida (Neuroptera sensu lato). Hymenopterans have retained many primitive morphological traits that have been lost or secondarily modified in most other holometabolous insects, including the Coleoptera and Neuropterida. This means that it is difficult to determine the correct evolutionary polarity of morphological characters informative about the earliest splits in the Hymenoptera, and different outgroups, such as Raphidioptera (Gibson 1993) and basal Lepidoptera (Vilhelmsen 1996), have been used in comparative studies of basal hymenopterans. For some difficult characters, combination of outgroup information from several lineages of holometabolous insects with data from hemimetabolous insects can elucidate the primitive state of the Hymenoptera. In other cases, the ground-plan state of the Hymenoptera remains elusive. Molecular analyses have yet to explore basal hymenopteran relationships in detail and the problem of rooting the hymenopteran tree.

\section{Symphyta}

The Hymenoptera are still often divided into the suborders Symphyta and Apocrita although the paraphyletic nature of the Symphyta has been recognized for a long time. Comparative morphological work through the last decades have convincingly resolved many of the higherlevel groupings in the 'Symphyta' and their relationship to the Apocrita (Fig. 2) (Vilhelmsen 1997; Ronquist et al. 1999; Vilhelmsen 1999). Several major clades have bootstrap support well exceeding 0.90 in phylogenetic analyses of morphological data. For instance, this is true for nonxyelid hymenopterans, core tenthredinoids (tenthredinoids excluding blasticotomids), the primitively wood- or stemboring lineages (Cephidae, Anaxyelidae, Siricidae, Xiphydriidae, Orussidae, and Apocrita), and Orussidae + 


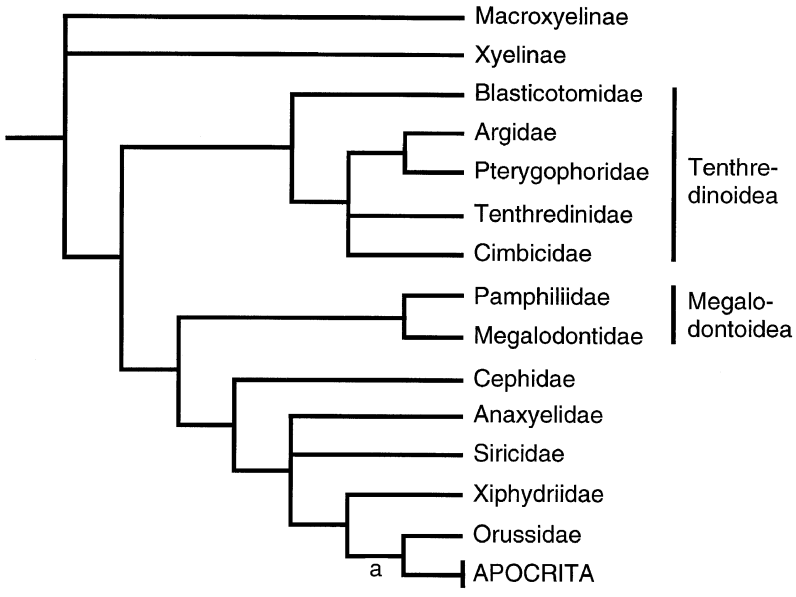

Fig. 2 Summary of what we know about relationships among extant symphytans. Solid lines represent well supported relationships, dashed lines suggested relationships. Note: a-Strongly supported by morphological data (two largely independent analyses), weakly contradicted by molecular data.

Apocrita (Fig. 2). Fossil groups fit well into the framework provided by the extant groups (Rasnitsyn 1988; Ronquist et al. 1999). Further work is particularly needed on the correct rooting of the basal Xyelinae-Macroxyelinaenonxyelid trichotomy, on the higher-level relationships among core tenthredinoids, and on the resolution of the anaxyelid-siricid-xiphydriid grade.

Relatively little work has been devoted to sawfly relationships below the family level (for an exception, see Gauld \& Mound 1982). With much of the larger framework established, the time is ripe for addressing questions about the circumscription of sawfly subfamilies, tribes and genera, and the affinities among them. The species-rich groups of core tenthredinoids provide the most difficult challenge in this context. At the same time, work on this group has perhaps the greatest potential of providing new insights into phylogeny and improving the current classification. Better understanding of tenthredinoid phylogeny will also allow testing of a wide range of interesting hypotheses about the evolution of insect-plant associations (e.g. Nyman et al. 1998).

Considering the wealth of morphological support for some of the higher symphytan groupings, sawflies should provide a good test for molecular data. So far, relatively few sawfly representatives have been examined and most work has been concentrated on only two mitochondrial sequences, 16S rDNA and cytochrome oxidase I (COI) (Carpenter \& Wheeler 1999; Dowton \& Austin 1999). Many of the early cladogenetic events in the Hymenoptera are obviously difficult to resolve with these sequences. Appropriate weighting results in some congruence with morphology-based trees but there are still major conflicts (Dowton \& Austin 1999; Ronquist et al. 1999). The most obvious clash concerns the sister group of the Apocrita. Morphological data strongly support Orussidae in this position (bootstrap support 1.00) whereas both $16 \mathrm{~S}$ and COI suggest the Siricidae (bootstrap support 0.72 for combined molecular data) (Dowton \& Austin 1977, 1999). The weight of the current evidence is in favour of the morphological alternative (Ronquist et al. 1999) but definite solution of this conflict must follow from further addition of morphological and molecular evidence, and from more sophisticated analysis of the data separately and combined (Carpenter \& Wheeler 1999). Such work should provide extremely valuable information on the relation between morphological and molecular evolution, and on the interpretation of phylogenetic results based on each of these types of data (Dowton \& Austin 1999).

\section{Parasitica}

The Apocrita are traditionally divided into the parasitic and aculeate wasps. Higher-level relationships among parasitic wasps are less well understood than those among symphytans or aculeates although there are some well established superfamily groupings such as the Ichneumonoidea, Chalcidoidea, Platygastroidea, Cynipoidea and Ceraphronoidea. Rasnitsyn's (1988) suggestion that the Apocrita fall into four major lineages grouping two and two (Fig. 3) has spurred much discussion, but only the trivial clades Ichneumonoidea and Aculeata were convincingly supported in a cladistic reanalysis of the data on which Rasnitsyn's hypothesis was originally based (Ronquist et al. 1999).

The Evaniomorpha are perhaps the most controversial of Rasnitsyn's major apocritan clades, combining groups as diverse as the Ceraphronoidea, Evanioidea, Megalyridae, Trigonalyidae and Stephanidae. Rasnitsyn (1988) erected the Evaniomorpha on the basis of a modification of the mesal mesocoxal articulation. This character is weak in two respects: (1) there is controversy concerning the state in the Stephanidae (see Ronquist et al. 1999); and (2) comparisons with Symphyta suggest that the evaniomorph state may be plesiomorphic for the Apocrita (Gibson

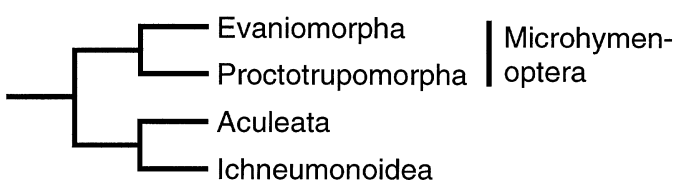

Fig. 3 Major apocritan relationships proposed by Rasnitsyn (1988). The Evaniomorpha comprise the Evanioidea, Ceraphronoidea, Megalyridae, Trigonalyidae and Stephanidae (see also Fig. 4). 
1999). No other morphological synapomorphies of the Evaniomorpha are known. Not surprisingly, cladistic reanalysis of Rasnitsyn's data indicates that the evaniomorphs form a grade of basal apocritan lineages rather than a monophyletic group (Ronquist et al. 1999). In particular, many morphological characters group ceraphronoids close to core proctotrupomorphs, such as chalcidoids, platygastroids, and diapriids.

In contrast, a recent molecular analysis of mitochondrial $16 \mathrm{~S}$ rDNA supports the Evaniomorpha as a monophyletic group (bootstrap support 0.89; stephanids not included) (Dowton et al. 1997). However, addition of a known stephanid sequence to the analysis caused anomalies, perhaps because of stephanid sequence idiosyncrasies or sequencing errors, casting some doubt on the result. The combined morphological and molecular analysis of higher hymenopteran relationships reported in this volume (Carpenter \& Wheeler 1999) places the Trigonalyidae as the most basal Apocritan lineage and separates it from the Evanioidea by two nodes that are well supported by molecular characters. These results agree well with the reanalysis of Rasnitsyn's data indicating that the Evaniomorpha form a paraphyletic grade of basal apocritan lineages (Ronquist et al. 1999). Nevertheless, evaniomorph relationships are regarded here as uncertain given the poor phylogenetic signal of the morphological data and the preliminary nature and incongruence of the molecular data (Fig. 4). Both molecular and morphological analyses support the monophyly of the Ceraphronoidea and the Evanioidea. Previous speculations that the Evanioidea may be an artificial grouping (Gauld \& Bolton 1988: 132) thus appear to be incorrect.

The Cynipoidea fall into five families: the Austrocynipidae, Ibaliidae, Liopteridae, Figitidae and Cynipidae (Ronquist 1995). There are no molecular analyses of higher-level cynipoid phylogeny but relationships among the families are well resolved based on extensive sets of morphological characters (Fig. 4) (Ronquist 1999). A few characters that are apparently in conflict with these relationships have been presented (Fergusson 1988, 1992; Rasnitsyn 1988). The interpretation of these characters is debated, but even if they are accepted as potential indicators of true relationships, their signal is swamped by the rest of the morphological characters (Ronquist 1999).

The current evidence thus suggests that the Cynipidae (gall wasps) and Figitidae together constitute the monophyletic 'microcynipoids', containing the bulk of cynipoid species, while the remaining depauperate families form a basal grade of wood-borer parasites (Fig. 4). The Austrocynipidae contain a single endemic Australian species being the sister group of all other cynipoids. Among other unique features, this species is the only cynipoid to have retained a true pterostigma.

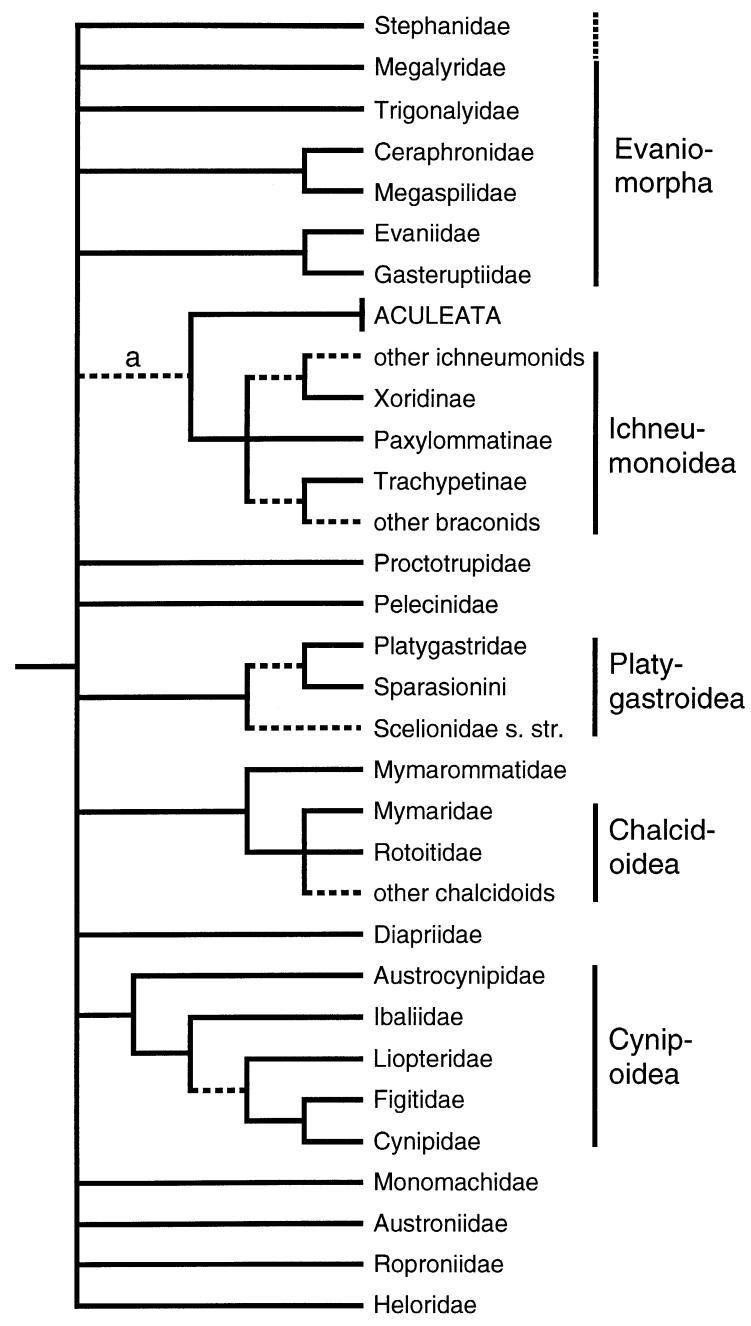

Fig. 4 Summary of what we know about relationships among parasitic wasps. Solid lines represent well supported relationships, dashed lines suggested relationships. Note: a-Weakly supported by molecular data, and by implied weighting of morphological data.

Phylogenetic relationships have been analysed to the species-level in the Ibaliidae and to the genus-level in the Liopteridae (Ronquist 1999 and references cited therein). Intergeneric relationships in the Cynipidae have also received considerable attention except for the species-rich tribe Cynipini, the oak gall wasps (Ronquist 1994; Liljeblad \& Ronquist 1998). The Figitidae remain the least known group phylogenetically, which is unfortunate considering their diversity and importance as biocontrol agents, as well as the considerable amount of controversy surrounding their classification (different subgroups are commonly raised to family level, e.g. Kovalev 1995, 1996). Nevertheless, several monophyletic figitid subgroups and 
some higher groupings can be tentatively identified based on the available evidence (Ronquist 1999). Most figitids are parasites of Diptera but phylogenetic patterns indicate that the common ancestor of microcynipoids was a parasite of a gall-inducing insect, and that this habit was retained in the most basal figitid lineages. Thus, the notion of figitids being primitively Diptera-parasitic (Rasnitsyn 1988) appears incorrect.

Rasnitsyn (1988) suggested a sister-group relationship between the Diapriidae and Cynipoidea but cladistic reanalysis of his data (Ronquist et al. 1999) indicates that this conclusion is uncertain. A molecular analysis (Dowton et al. 1997) placed the Cynipoidea as the most basal group of the Apocrita, admittedly without convincing bootstrap support, but several morphological and biological characters are difficult to reconcile with such a position of the cynipoids. For instance, in contrast to many other major groups of parasitic wasps, all cynipoids (except the gall wasps) are endoparasitic in early larval instars, a life-history trait believed to be derived within the Apocrita.

The monophyly of the Chalcidoidea and their sistergroup relationship with the Mymarommatoidea are well supported, but there is still no cladistic analysis of familial relationships across the Chalcidoidea (Gibson et al. 1999). Several chalcidoid families are supported as monophyletic by at least one putative synapomorphy, but others are likely to be para-or polyphyletic. Both morphological and molecular evidence suggest that the Mymaridae form the sister group of the remaining chalcidoids, with some uncertainty concerning the position of the Rotoitidae due to missing data.

The basal position of mymarommatids and mymarids relative to the remaining chalcidoids raises intriguing questions concerning the ancestral biology of chalcidoids. Nothing is known about mymarommatid biology, but their small size indicates that they are egg parasitoids like mymarids. Thus, it is possible that the ancestral chalcidoid was a small egg parasitoid and not an ectoparasitoid of wood-boring insect larvae, as has been commonly assumed. However, further study of the phylogenetic position of mymarids and elucidation of the biology of mymarommatids are needed to determine whether mymarommatid and mymarid biologies are likely to be homologous and not independently derived.

The monophyly of the Platygastroidea is well established (Austin \& Field 1997) but their position within the Apocrita has been debated. Rasnitsyn (1988) suggested that they may be related to chalcidoids and mymarommatids but cladistic reanalysis of his data fails to support this conclusion convincingly (Ronquist et al. 1999). Gibson (1999) summarises all the morphological evidence pertaining to this issue known currently and concludes that the
Platygastroidea are more likely to form a monophyletic group with the Proctotrupoidea sensu stricto than with the Chalcidoidea + Mymarommatidae. In contrast, molecular analyses have supported Rasnitsyn's notion of a platygastroid-chalcidoid connection repeatedly, although again not convincingly (Dowton \& Austin 1994; Dowton et al. 1997).

Within Platygastroidea, the Platygastridae form an obviously derived, reductional offshoot of the more plesiomorphic and poorly defined, and hence probably paraphyletic Scelionidae. However, ovipositor characters indicate that the Scelionidae actually do form a monophyletic group provided that the small tribe Sparasioninini, which is more closely related to platygastrids, is excluded (Austin \& Field 1997) (Fig. 4).

More effort has perhaps been devoted to the phylogeny of the Ichneumonoidea than to any other superfamily of parasitic wasps. A number of subfamilies and other major lineages have been identified as monophyletic (e.g. Gauld 1985; Wahl 1993; Wahl \& Gauld 1998), but the relationships among them is still unsatisfactorily resolved and some groupings are controversial. In the Braconidae, it appears now that the Trachypetinae form the most basal clade and that the cyclostomes are monophyletic, but the position of other braconid groups remains uncertain (Belshaw et al. 1998; Quicke et al. 1999a). Morphological analyses have thus far failed to convincingly resolve the basal phylogeny of ichneumonids, particularly the position of fossil groups of putative ichneumonid affinity (Quicke $e t$ al. 1999a), but work in progress may change this situation. The extant Paxylommatinae, usually considered ichneumonids (e.g. Sharkey \& Wahl 1992), come out as the sister group of braconids in some analyses and as a basal ichneumonid clade in others (Quicke et al. 1999a; Quicke et al. 1999c). There is some suggestion from both morphological and molecular characters (28S rDNA) that the Xoridinae form the sister group of the remaining extant ichneumonids (Quicke et al. 1999a, c). However, other analyses of morphological data indicate that the Xoridinae instead belong to an ichneumonid subclade that includes the Pimpliformes, Ichneumoninae, Cryptinae, and a few other subfamilies (Wahl \& Gauld 1998).

Rasnitsyn's (1988) proposal of a sister-group relationship between the Ichneumonoidea and Aculeata is based on the shared presence in these groups of ovipositor valvilli and propodeal condyli. An additional feature that may be synapomorphic is the presence of well developed spiracles on abdominal segments $2-7$. This first appears to be an obvious plesiomorphy, but the reduction of these spiracles in all other Apocrita as well as in the Orussidae, the sister group of Apocrita, suggests that the well developed spiracles in ichneumonoids and aculeates may represent a 
secondary reversal (Ronquist et al. 1999). This reversal would be an example of neoteny, since the spiracles are well developed in the larvae of most Apocrita. However, there are also many morphological characters grouping ichneumonoids with proctotrupomorph lineages as shown by unweighted parsimony analysis of Rasnitsyn's data (Ronquist et al. 1999). When Aculeata + Ichneumonoidea is included in this summary as a tentative group (Fig. 4), it is because of congruence between results of preliminary molecular analysis (Dowton \& Austin 1994; Dowton et al. 1997; Carpenter \& Wheeler 1999) and morphological analysis using implied weights (Ronquist et al. 1999).

\section{Aculeata}

In the first Hennigian analysis of higher hymenopteran relationships, based on ovipositor characters, Oeser (1961) established that the Aculeata are monophyletic and fall into two lineages, the Chrysidoidea and the Aculeata sensu stricto. Subsequent morphological analyses have supported this dichotomy (Fig. 5) (Brothers 1975; Brothers \& Carpenter 1993; Ronquist et al. 1999).

Comparative morphological work on the Chrysidoidea has resulted in two widely different hypotheses about relationships, one based on explicit cladistic analysis (Carpenter 1986; Brothers \& Carpenter 1993), the other on narrative character argumentation (Rasnitsyn 1988). Cladistic reanalysis of the data on which the latter was

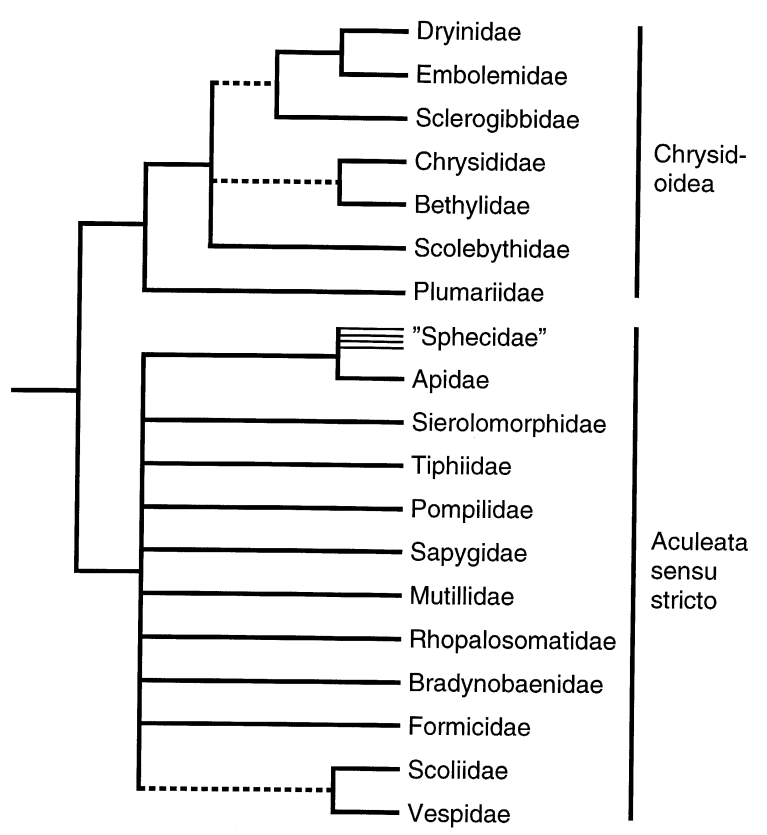

Fig. 5 Summary of what we know about aculeate relationships. Solid lines represent well supported relationships, dashed lines suggested relationships. based removes much of the conflict between the two (Ronquist et al. 1999). Thus in terms of quantitative cladistic analysis, there is agreement in morphological characters concerning the sister-group relationship between dryinids and embolemids, and the basal position of the Plumariidae (Fig. 5). There are also indications that the Chrysididae and Bethylidae form sister groups and that sclerogibbids may be related to dryinids and embolemids (Fig. 5), whereas the position of the Scolebythidae remains uncertain. Within chrysidoid families, there has been some work on generic, tribal, and subfamily relationships (Carpenter 1999 and references cited therein).

In the Vespoidea, there is still considerable uncertainty concerning higher-level relationships. In terms of bootstrap values, there is no above-family clade with convincing support in any of the morphology-based cladistic analyses, with the possible exception of the sister-group relationship between vespids and scoliids (Fig. 5) (Ronquist et al. 1999). Even the monophyly of the Vespoidea itself has not been reliably established. Brothers (1999) takes a somewhat more optimistic attitude based on the analysis presented by Brothers and Carpenter (1993), but acknowledges that several of the indicated relationships are only poorly supported, notably those of the Rhopalosomatidae and Pompilidae. Brothers (1999) reviews the work on vespoid relationships below the family level, and presents a new phylogenetic analysis of tribal relationships in the Mutillidae.

It has long been understood that the bees (Apidae sensu lato) form a monophyletic lineage derived from some subgroup of digger wasps (Sphecidae sensu lato) but it has been unclear exactly what that subgroup may be. Finally, it appears that morphology-based cladistic analyses are approaching a solution to this question (see Brothers 1999). Hopefully, this will eventually lead to a stable classification for the Apoidea and a better understanding of their evolution.

Molecular work on the higher-level phylogeny of the Aculeata is still in its infancy, and currently do not provide any new insights into higher-level aculeate relationships (Carpenter \& Wheeler 1999).

\section{Prospects}

Although the current understanding of higher hymenopteran relationships is considerably better than two decades ago, we are till far from being able to answer some of the most intriguing questions concerning the evolution of hymenopterans. For instance, Hamilton (1978) speculated that much of the morphological diversification of apocritans took place in forms that were associated with dead or dying trees but the phylogenetic data are still too poor to rigorously test this hypothesis. Another problem that has been much discussed is 
the relation between internal and external parasitoids (e.g. Whitfield 1992). It has been assumed that apocritans were originally ectoparasitic and that the transition to endoparasitism occurred repeatedly and was irreversible. Again, the phylogenies are still too unresolved to allow detailed reconstruction of the evolution of this life-history character in the major apocritan lineages.

The rapid progress in recent decades in resolving higher symphytan relationships based on comparative morphological data gives hope that the seemingly difficult basal apocritan relationships, particularly those among parasitic wasps, will eventually yield to the same approach. Parasitic wasps are more diverse than symphytans but have received less attention in morphological studies and the available evidence has not been used fully in analysing relationships. The only morphology-based cladistic analysis addressing nonaculeate apocritan relationships (Ronquist et al. 1999) is restricted to character systems known in 1988 and several new character systems have been studied since then. Data informative about higher apocritan relationships are continuously added (e.g. Basibuyuk \& Quicke 1999; Isidoro et al. 1999) and several interesting character complexes, such as the musculature of the pro- and mesothorax, remain to be studied. Thus, continued efforts to study the comparative morphology of apocritans and use this information in analysing higher relationships are likely to be productive. The most valuable studies in this context will be those that include broad, well balanced representation of higher groups and use techniques that allow detailed study of internal and external structure, such as scanning electron microscopy and serial sectioning.

Relationships of higher aculeates have been studied more intensively than those of symphytans and parasitic wasps. Yet, most of the characters that have been employed are external morphological features that can be studied without dissection of specimens. Therefore, the failure of existing analyses to resolve many higher aculeate relationships convincingly, particularly in the Vespoidea and Apoidea, is not a failure of morphological data per se. Broad comparative morphological studies are also likely to yield new information useful in resolving higher aculeate relationships, particularly studies focusing on internal or external character systems that are not visible without dissection.

Fossil data have spurred much of the development of hymenopteran phylogenetics (e.g. Rasnitsyn 1988) and will undoubtedly continue to play an important role in the future (e.g. Basibuyuk et al. 1999; Ronquist 1999). An urgent task is to include well-preserved and well-dated key fossils among recent taxa in quantitative morphologybased phylogenetic analyses. Such fossils may provide critical information in resolving higher relationships and, to the extent that their phylogenetic position can be determined reliably, will also allow dating of cladogenetic events during the early hymenopteran radiation. Dated phylogenies are important in many contexts, for instance in understanding the relative timing of events in the coevolution between hymenopterans and their hosts or host plants. Some attempts to include fossils in cladistic analyses have been made (e.g. Quicke et al. 1999a; Ronquist et al. 1999) but much fruitful research remains at the interface between palaeoentomology, comparative morphology and phylogenetics. Obviously, further study of the comparative morphology of extant hymenopterans is instrumental to progress in this area.

Molecular analyses of higher hymenopteran relationships are still in their infancy but will undoubtedly play an increasingly important role in the future. Currently, molecular data are often used to address problem areas in morphological phylogenies, but increasing attention should be paid to the congruence between morphological and molecular results. Only once there is agreement between strong molecular and morphological phylogenetic signals, or we understand why the signals are different, will we be able to trust molecular results when morphological results are weak, and vice versa. Therefore, molecular studies that concentrate on relationships that are reliably resolved with morphological data are well worth pursuing, e.g. higher symphytan or cynipoid relationships. Such studies are likely to increase our understanding of molecular and morphological evolution, and in evaluating results of phylogenetic analyses based on either of these types of character data. In this context, conflict between morphology and molecules is as interesting as agreement. Eventually, morphological and molecular (and other types of data) should be combined in simultaneous analyses of higher relationships (Carpenter \& Wheeler 1999).

Commonly, phylogenies are extremely asymmetric and one or a few species may form the sister group of a major clade. These few species are critical in reconstructing relationships and in understanding the evolution of the group to which they belong. If they are rare, phylogeneticists often have to rely on material collected a long time ago. For optimal results, both molecular and morphological studies require specimens preserved with special techniques; standard pinned specimens are often inferior or even useless. Therefore, increased attention should be paid to preservation techniques when collecting material of rare, phylogenetically interesting taxa (Quicke et al. 1999b).

Hopefully, we will see swift progress in hymenopteran phylogenetics in the decade to come. In view of the fundamental importance of phylogenies in biology, this would be a crucial step forward in our understanding of the Hymenoptera. 


\section{Acknowledgements}

The symposium and workshop on the higher level phylogeny of the Hymenoptera had not been possible without financial support from Stiftelsen för zoologisk forskning in Uppsala, the Faculty of Science and Technology at Uppsala University, the Swedish Natural Science Foundation, and the Norwegian Academy of Science and Letters through Zoologica Scripta.

\section{References}

Austin, A. D. \& Field, S. A. (1997). The ovipositor system of scelionid and platygastrid wasps (Hymenoptera:

Platygastroidea): Comparative morphology and phylogenetic implications. Invertebrate Taxonomy, 11, 1-87.

Basibuyuk, H. H. \& Quicke, D. L. J. (1999). Gross morphology of multiporous plate sensilla in the Hymenoptera (Insecta). Zoologica Scripta, 28, 51-67.

Basibuyuk, H. H., Rasnitsyn, A. P., Achterberg, C. V., Fitton, M. G. \& Quicke, D. L. J. (1999). A new, putatively primitive Cretaceous fossil braconid subfamily from New Jersey amber (Hymenoptera: Braconidae). Zoologica Scripta, 28, 211-214.

Belshaw, R., Fitton, M., Herniou, E., Gimeno, C. \& Quicke, D. L. J. (1998). A phylogenetic reconstruction of the Ichneumonoidea (Hymenoptera) based on the D2: variable region of $28 \mathrm{~S}$ ribosomal RNA. Systematic Entomology, 23, 109-123.

Brothers, D. B. (1975). Phylogeny and classification of the aculeate Hymenoptera, with special reference to Mutillidae. University of Kansas Science Bulletin, 50, 483-648.

Brothers, D. J. (1999). Phylogeny and evolution of wasps, ants, and bees (Hymenoptera, Chrysidoidea, Vespoidea, and Apoidea). Zoologica Scripta, 28, 233-249.

Brothers, D. J. \& Carpenter, J. M. (1993). Phylogeny of Aculeata: Chrysidoidea and Vespoidea. Fournal of Hymenoptera Research, 2, 227-302.

Carpenter, J. M. (1986). Cladistics of the Chrysidoidea (Hymenoptera). Fournal of the New York Entomological Society, 94, 303-330.

Carpenter, J. (1999). What do we know about chrysidoid (Hymenoptera) relationships? Zoologica Scripta, 28, 215-231.

Carpenter, J. C. \& Wheeler, W. C. (1999). Towards simultaneous analysis of morphological and molecular data in Hymenoptera. Zoologica Scripta, 28, 251-260.

Dowton, M. \& Austin, A. D. (1994). Molecular phylogeny of the insect order Hymenoptera: apocritan relationships. Proceedings of the National Academy of Sciences of the United States of America, 91, 9911-9915.

Dowton, M. \& Austin, A. D. (1997). Evidence for ATtransversion bias in wasp (Hymenoptera: Symphyta) mitochondrial genes and its implications for the origin of parasitism. Fournal of Molecular Evolution, 44, 398-405.

Dowton, M. \& Austin, A. D. (1999). Models of analysis for molecular datasets for the reconstruction of basal hymenopteran relationships. Zoologica Scripta, 28, 69-74.

Dowton, M., Austin, A. D., Dillon, N. \& Bartowsky, E. (1997). Molecular phylogeny of the apocritan wasps: The Proctotrupomorpha and Evaniomorpha. Systematic Entomology, $22,245-255$.
Fergusson, N. D. M. (1988). A comparative study of the structures of phylogenetic importance of female genitalia of the Cynipoidea (Hymenoptera). Systematic Entomology, 13, $13-30$.

Fergusson, N. (1992). A remarkable new genus and species of Cynipoidea (Hymenoptera) from Papua New Guinea. Fournal of Natural History, 26, 659-662.

Gaston, K. J. (1991). The magnitude of global insect species richness. Conservation Biology, 5, 283-293.

Gauld, I. D. (1985). The phylogeny, classification and evolution of parasitic wasps of the subfamily Ophioninae (Ichneumonidae) Bulletin of the British Museum (Natural History) Entomology, 49, 235-339.

Gauld, I. \& Bolton, B., eds. (1988). The Hymenoptera. Oxford University Press, Oxford.

Gauld, I. D. \& Mound, L. A. (1982). Homoplasy and the delineation of holophyletic genera in some insect groups. Systematic Entomology, 7, 73-86.

Gibson, G. A. P. (1993). Groundplan structure and homology of the pleuron in Hymenoptera based on a comparison of the skeletomusculature of Xyelidae (Hymenoptera) and Raphidiidae (Neuroptera). Memoirs of the Entomological Society of Canada, 165, $165-187$.

Gibson, G. (1999). Sister group relationships of the Platygastroid and chalcidoidea (Hymenoptera) an alternate hypothesis to Rasnitsyn (1988). Zoologica Scripta, 28, 125-138.

Gibson, G., Heraty, J. M. \& Woolley, J. B. (1999). Phylogenetics and classification of Chalcidoidea and Mymarommatoidea - a review of current concepts (Hymenoptra, Apocrita). Zoologica Scripta, 28, 87-124.

Hamilton, W. D. (1978). Evolution and diversity under bark. In: Mound, L. A. \&, Waloff, N. (Eds.) Diversity of Insect Faunas. pp. 154-175, Blackwell, Oxford.

Isidoro, N., Bin, F., Romani, R., Pujade, J. \& Ros, P. (1999). Diversity and function of male antennal glands in Cynipoidea (Hymenoptra). Zoologica Scripta, 28, 165-174.

Kovalev, O. V. (1995). Paleontological history, phylogeny, and systematics of Brachycleistogastromorpha, Infraorder N. and Cynipomorpha Infraorder N. (Hymenoptera) with descriptions of new fossil and recent families, subfamilies, and genera. Entomological Review, 74, 105-147.

Kovalev, O. V. (1996). New higher taxa of cynipoids (Hymenoptera, Cynipoidea): Renaming of a family and description of a new family, new subfamily and genus. Entomologicheskoe Obozrenie, 75, 408-416.

Kristensen, N. P. (1991). Phylogeny of extant hexapods. In: Naumann, I. D., Carne, P. B., Lawrence, J. F., Nielsen, E. S., Spradbery, J. P., Taylor, R. W., Whitten, M. J. \&, Littlejohn, M. J. (Eds.) The Insects of Australia. pp. 125-140, Melbourne University Press, Melbourne.

Liljeblad, J. \& Ronquist, F. (1998). A phylogenetic analysis of higher-level gall wasp relationships. Systematic Entomology, 23, 229-252.

Nyman, T., Roininen, H. \& Vuorinen, J. A. (1998). Evolution of different gall types in willow-feeding sawflies (Hymenotpera: Tenthredinidae). Evolution, 52, 465-474.

Oeser, R. (1961). Vergleichend-morphologische Untersuchungen über den ovipositor der Hymenopteren. Mitteilungen aus dem Zoologischen Museum in Berlin, 37, 3-119. 
Quicke, D. L. J., Basibuyuk, H. H., Fitton, M. G. \& Rasnitsyn, A. P. (1999a). Morphological, palaeontological and molecular aspects of ichneumonoid phylogeny (Hymenoptera, Insecta) Zoologica Scripta, 28, 175-201.

Quicke, D. L. J., Belshaw, R. \& Lopez-Vaamonde, C. (1999b). Preservation of hymenopteran specimens for subsequent molecular and morphological study. Zoologica Scripta, 28, 261-267.

Quicke, D. L. J., Lopez-Vaamonde, C. \& Belshaw, R. (1999c). The basal Ichneumonidae (Insecta: Hymenoptera): 28S D2 rDNA considerations of the Brachycyrtinae, Labeninae, Paxylommatinae and Xoridinae. Zoologica Scripta, 28, 203 210.

Rasnitsyn, A. P. (1988). An outline of evolution of the hymenopterous insects. Oriental Insects, 22, 115-145.

Ronquist, F. (1994). Evolution of parasitism among closely related species: Phylogenetic relationships and the origin of inquilinism in gall wasps (Hymenoptera, Cynipidae).

Evolution, 48, 241-266.

Ronquist, F. (1995). Phylogeny and early evolution of the Cynipoidea (Hymenoptera). Systematic Entomology, 20, 309-335.

Ronquist, F. (1999). Phylogeny, classification and evolution of the Cynipoidea. Zoologica Scripta, 28, 139-164.

Ronquist, F., Rasnitsyn, A. P., Roy, A., Eriksson, K. \& Lindgren, M. (1999). Phylogeny of the Hymenoptera: A cladistic reanalysis of Rasnitsyn's (1988) data. Zoologica Scripta, 28, 13-50.
Sharkey, M. J. \& Wahl, D. B. (1992). Cladistics of the Ichneumonoidea. Fournal of Hymenoptera Research, 1, 15-24.

Vilhelmsen, L. (1996). The preoral cavity of lower Hymenoptera (Insecta): comparative morphology and phylogenetic significance. Zoologica Scripta, 25, 143-170.

Vilhelmsen, L. (1997). The phylogeny of lower Hymenoptera (Insecta), with a summary of the early evolutionary history of the order. Fournal of Zoological Systematics and Evolutionary Research, 35, 49-70.

Vilhelmsen, L. (1999). The occipital region in the basal Hymenoptera (Insecta): a reappraisal. Zoologica Scripta, 28, 7585.

Wahl, D. B. (1993). Cladistics of the ichneumonid subfamily Labeninae (Hymenoptera: Ichneumonidae). Entomologia Generalis, 18, 91-105.

Wahl, D. B. \& Gauld, I. D. (1998). The cladistics and higher classification of the Pimpliformes. Systematic Entomology, 23, 265-298.

Whitfield, J. B. (1992). Phylogeny of the non-aculeate Apocrita and the evolution of parasitism in the Hymenoptera. Fournal of Hymenoptera Research, 1, 3-14.

Whiting, M. F., Carpenter, J. C., Wheeler, Q. D. \& Wheeler, W. C. (1997). The Strepsiptera problem: Phylogeny of the holometabolous insect orders inferred from $18 \mathrm{~S}$ and $28 \mathrm{~S}$ ribosomal DNA sequences and morphology. Systematic Biology, 46, 1-68. 